intercourse $(\mathrm{B}=-0.03, \mathrm{CI}=-0.04,-0.01)$ may lead to higher adulthood BMI.

Conclusion The findings of this study present strong evidence for causal interplay between adiposity and women's RFs and future studies should consider adiposity when investigating risk of RFs, whether as a potential confounder or mediator, on disease risk.

\section{P13 HOW HAVE UK MATERNAL HEALTH SERVICES CHANGE IN RESPONSE TO THE COVID-19 PANDEMIC? - A SYSTEMATIC REVIEW}

${ }^{1}$ Hannah Beetham*, ${ }^{2}$ Lisa Hurt, ${ }^{3}$ Lauren Copeland. 'School of Medicine, Cardiff University, Cardiff, UK; ${ }^{2}$ Division of Population Medicine, Cardiff University, Cardiff, UK; ${ }^{3}$ DECIPHer School of Social Sciences, Cardiff University, Cardiff, UK

10.1136/jech-2021-SSMabstracts. 103

Rationale Many expectant and new mothers have been impacted by the restructuring of maternal services that has occurred in response to the pandemic. Although there is hopefully an end in sight, restrictions may continue for some months. It is therefore important to assess the changes that have occurred, in order to prevent further harm to mothers, or to realise and implement any positive changes permanently. Aim: To analyse the different ways in which antenatal, obstetric, and postnatal services in the UK have adapted to the COVID-19 pandemic.

Methods Key-word searches were used to systematically scope three databases for papers that reported on any aspect of maternal care or services and COVID-19 until 03/12/2020. In total, 2,299 papers' titles and abstracts were screened according to pre-set eligibility criteria. Half were double-screened by a second researcher, and discrepancies were discussed between three researchers until resolved. Full-text screening $(n=344)$ excluded papers that weren't relevant, or didn't include primary data. Excluded papers and papers that the lead researcher flagged for a second opinion were checked by a second researcher. At this point, the decision was made to focus on UK services, due to the high number of papers. Next steps will be to extract data from the final sample of papers $(n=12)$ and appraise their quality. Narrative synthesis will form a coherent report on how services in the UK have changed.

Results Preliminary results show that there have been shifts in some maternal services towards virtual delivery. Additionally, there has been a change in the number of antenatal and postnatal appointments, including the number and nature of antenatal emergency presentations. There has also been a reduction in the care choices available to pregnant women, including changes to birth plans. Furthermore, there have been changes to obstetric unit layouts and care delivery, including changes to the rates of C-sections and general anaesthesia. Additional results will be submitted before the June 28th.

Population Health Relevance This review is expected to highlight some interesting changes that have occurred in UK maternal services since the beginning of the pandemic. Some may have changed maternal services for the better, while others may highlight some difficulties that new mothers have faced, and will be important to address in case of continuing restrictions or future pandemics. Further research will focus on qualitatively assessing the experiences of new mothers during the pandemic, to gain first-hand insights into how they were affected by the changes.

\section{P14 NEO-MALTHUSIANISM IN THE CONCEPTION OF THE FAMILY PLANNING FRAME: THE ROLE OF THE FORD FOUNDATION IN POPULATION CONTROL IN CHINA AND INDIA}

${ }^{3}$ Tiasangla Longkumer*. ' Centre of Social Medicine and Community Health, Jawaharlal Nehru University, Delhi, India; ${ }^{2}$ Harvard Yenching Institute, Harvard University, Cambridge, USA; ${ }^{3}$ Institute of Chinese Studies, Think Tank, Delhi, India

\subsection{6/jech-2021-SSMabstracts. 104}

Background The second half of the 20th century experienced the rise of demography as a discipline with huge outpouring of technical aid and resources to curb the population of the developing nations with a special focus on Asia. China and India figured in the imagination of these demographers who believed Neo Malthusian theory of positive checks on population control. The theory of Neo Malthusianism took precedence among senior technocrats, demographers and government officials in the 1950s and 60s. China experienced the peak of Neo Malthusianism with the one-child policy in the late 1970s and India with the Emergency in the early 1970s.

Methods Tracing the conceptual understanding of Neo-Malthusianism which was the theoretical backbone of Ford's population control programmes, this paper would encompass the historical development of the Family Planning program in independent India and socialist China with a sight on the various important actors involved, the geopolitical context of Ford's entry, strategies adopted and the implications of Family planning on the health systems.Using archival research, secondary literatures and key informant interviews, this study adopts a qualitative method and aims to study the efforts of the Ford Foundation to promote, advance and institutionalize population control through the Family Planning program in China and India.

Data The study primarily draws on archival data namely government correspondence, memoranda, notes, reports, personal papers of some of the important actors, minutes of meetings, manuscripts of memoirs and autobiographies, reports of committees and commissions, working papers, theses and secondary references. Archival research was conducted at the Rockefeller Archive Centre, Harvard University Archives, Columbia University Ford Foundation collections online. Secondary literatures particularly the writings of John C. Caldwell, Gyan Prakash, Dwight Macdonald, Mohan Rao, Matthew Connelly, Susan Greenhalgh and several others have been consulted. Key informants included Dr. Lincoln Chen and Dr. Shirish Kavadi.

Discussion By the early 1950s, the growing population of China and India became a source of high concern in the west and the eastern elites. Complementary to the voiced concern for growing number of Chinese and Indians, another important precursor of the Ford Foundation efforts was the changing political landscape. The formation of the Marshall plan, India's action towards curbing population growth in the 1950s and recommendations of the 1948 field trip in the Far East induced Ford's population control activities and changed the discourse of population health in China and India. 